\title{
TPH2 gene polymorphisms in the regulatory region are associated with paranoid schizophrenia in Northern Han Chinese
}

\author{
X.M. Xu, M. Ding, H. Pang and B.J. Wang \\ Department of Forensic Medicine, China Medical University, \\ Shenyang, China \\ Corresponding author: B.J. Wang \\ E-mail: bjwang@mail.cmu.edu.cn \\ Genet. Mol. Res. 13 (1): 1497-1507 (2014) \\ Received October 30, 2012 \\ Accepted June 26, 2013 \\ Published March 12, 2014 \\ DOI http://dx.doi.org/10.4238/2014.March.12.1
}

\begin{abstract}
In the last years, serotonin (5-HT) has been related with the pathophysiology of several psychiatric disorders, including schizophrenia. Thus, genes related to the serotonergic (5-HTergic) system are good candidate genes for schizophrenia. The rate-limiting enzyme of 5-HT synthesis is tryptophan hydroxylase 2 (TPH2). Single nucleotide polymorphisms (SNPs) in the regulatory regions of TPH2 gene may affect gene expression and biosynthesis of 5-HT triggering to various neuropsychiatric disorders related to 5-HT dysfunction. The present study explored the association of SNPs within the TPH2 gene with paranoid schizophrenia in Han Chinese. A total of 164 patients with schizophrenia and 244 healthy controls were genotyped for six TPH2 SNPs (rs4570625, rs11178997, rs11178998, rs41317118, rs17110747, and rs41317114). Significant group differences were observed in the allele and genotype frequencies of rs4570625 and in the frequencies of GTA and TTA haplotypes corresponding to rs4570625-rs11178997rs11178998. Our findings suggest that common genetic variations of TPH2 are likely to contribute to genetic susceptibility to paranoid schizophrenia in Han Chinese. Further studies in larger samples are
\end{abstract}


needed to replicate this association.

Key words: TPH2; 5-HT; Paranoid schizophrenia; Haplotype; Serotonin; SNP

\section{INTRODUCTION}

Schizophrenia is a complex disorder affecting approximately $1 \%$ of the population worldwide (Schwab and Wildenauer, 2008) with the paranoid type being more common. The etiology of schizophrenia remains unclear. A genetic basis of schizophrenia has been observed in family (Tsuang et al., 1985), twin (Sullivan et al., 2003), and adoption studies (Heston, 1966), and its heritability is estimated at approximately 80 to $85 \%$ (Cardno and Gottesman, 2000). Recent advances in human genome information and molecular biology techniques have facilitated significant progress in genetic studies of schizophrenia. A number of important candidate genes have been cloned and their preliminary positions identified. These genes are closely related to function, and thus have revealed broad contours of disease-related signaling pathways.

Serotonin (5-hydroxytryptamine, or 5-HT) is a monoamine neurotransmitter synthesized in the raphe nuclei of the brain stem and involved in the control of a wide range of physiological events within the central nervous system. Accordingly, disruption of serotonergic (5-HTergic) function has been implicated in the pathogenesis of many psychiatric disorders, including schizophrenia (Abi-Dargham et al., 1997), and drugs targeting the 5-HTergic system are widely used for the treatment of various psychiatric diseases. Tryptophan hydroxylase (TPH), the rate-limiting enzyme in 5-HT biosynthesis, converts the amino acid tryptophan to 5-hydroxytrytophan, which is then decarboxylated into 5-HT. Thus, TPH has received a great attention in genetic studies of schizophrenia. To date, two TPH genes have been identified. The TPH1 gene is located on chromosome $11 \mathrm{p} 15$ and has been studied as a candidate gene for schizophrenia (Paik et al., 2000), but TPH1 is mainly expressed in the peripheral tissues. The TPH2 gene was recently described as a fairly large gene of $93.5 \mathrm{~kb}$ with 11 exons located on chromosome 12q21.1. TPH2 is expressed at high levels in the human brain but only at very low levels in other tissues (Zill et al., 2004a) and shows 72\% sequence homology to TPH1. Moreover, total RNA samples from wild type mice (TPH+/+) revealed about 150 fold more TPH 2 than TPH1 mRNA in the brain stem, suggesting that TPH2 may play a more important role in 5-HT synthesis in the brain (Walther et al., 2003). Therefore, TPH2 may also be a candidate gene for schizophrenia.

Genetic variation of TPH1 has previously been associated with schizophrenia risk (Zaboli et al., 2006; Anttila et al., 2007). A meta-analysis showed a significant association between TPH1 218A/C and schizophrenia ( $\mathrm{Li}$ and $\mathrm{He}, 2006 \mathrm{~b}$ ). The newly updated schizophrenia gene meta-analysis revealed that TPH1 is one of the four genes positively associated with schizophrenia, showing strong epidemiological credibility (Allen et al., 2008). In contrast to TPH1, genetic studies have shown an association between TPH2 and suicidal behavior (Zill et al., 2004b; Li and He, 2006a), major depression (Zill et al., 2004c), panic disorder (Maron et al., 2007), chronic fatigue syndrome (Goertzelet et al., 2006; Smith et al., 2006) and Tourette syndrome (Mössner et al., 2007). However, no evidence has been found for a role of TPH 2 in schizophrenia, despite several studies in this area (De Luca et al., 2005a; Higashi et al., 2007; Shiroiwa et al., 2010; Tee et al., 2010; Kim and Yoon, 2011; Zhang et al., 2011). It is noteworthy that a certain number of these studies focused mainly on the rs 4570625 $(-703 \mathrm{G} / \mathrm{T})$, a common polymorphic SNP in the putative promoter (Kennedy et al., 2003) that has 
been reported to be associated with the attention deficit hyperactivity disorder (ADHD) (Walitza et al., 2005), emotional processing (Herrmann et al., 2007), personality traits, and disorders related to emotional dysregulation (Gutknecht et al., 2007; Reuter et al., 2007). The promoter polymorphism rs 4570625 of TPH2 has been also found to affect the responsiveness of the amygdala, a structure critically involved in the regulation of emotional behaviors (Brown et al., 2005; Canli et al., 2005). Moreover, neuroimaging studies have shown that abnormal amygdala activity during emotional stimuli processing appears to be associated with augmentation of positive symptoms, especially paranoia (Goghari et al., 2010). However, a recent study suggested that rs4570625 might also play an important role in the development of positive symptoms of schizophrenia in Han Chinese (Zhang et al., 2011). These findings prompted us to further investigate whether TPH 2 is a susceptibility gene for paranoid schizophrenia in the Han Chinese.

In particular, the aim of the present study was to investigate the association between paranoid schizophrenia in the Han Chinese and specific SNPs within TPH2, including rs4570625, and five additional SNPs that have received little or no attention to date (rs11178997, rs11178998, rs41317118, rs17110747, and rs41317114).

\section{MATERIAL AND METHODS}

\section{Subjects}

All subjects were ethnically Han Chinese. This case-control study involved 164 unrelated in-patients with paranoid schizophrenia (87 males; 77 females; mean age 45.0 \pm 12.8 years) recruited from the Kaiyuan mental hospital in Liaoning Province, China. Patients were diagnosed by at least two psychiatrists according to the Diagnostic and Statistical Manual of Mental Disorders (DSM-IV) criteria and the Chinese Classification of Mental Disorders (CCMD3) for schizophrenia. The control group consisted of 244 unrelated healthy volunteers (126 males; 118 females; mean age $38.5 \pm 16.2$ years) free from present, past and family history of psychiatric illness. This study was approved by the Medical Research Ethics Committee at China Medical University, and informed consent was obtained from all subjects.

\section{Genotyping}

A 5-mL peripheral blood sample was obtained from each subject for extraction of genomic DNA. In particular, genomic DNA was extracted from leukocytes using a standard phenol-chloroform method. Two fragments that included the six SNPs of interest were amplified from the extracted DNA by PCR. SNPs were genotyped by DNA sequencing analysis using primers shown in Table 1.

\section{Statistical analysis}

Hardy-Weinberg equilibrium, linkage disequilibrium (LD) and allele-based association analyses of single markers, as well as haplotype analyses, were calculated using Haploview version 4.2. The chi-square test was performed in order to compare genotypic frequencies between schizophrenic patients and controls using the Statistical Analysis System (SAS) V.12.0 statistical package. All tests were two-tailed, and significance was set at 0.05 . 
Table 1. Primers used for amplification of the TPH2 gene.

\begin{tabular}{lcl}
\hline Region & Fragment length & Primer \\
\hline Promoter/exon 1 & 905 bp & Forward (-792): 5'-tgcatagaggcatcacagga-3' \\
exon 11/3'flanking & 1104 bp & Reverse (113): 5'-agcagggggtactagagg-3' \\
& & Forward (92692): 5'-attacccgttccttctca-3' \\
& & Reverse (93795): 5'-caagcactgggacgaat-3' \\
\hline
\end{tabular}

\section{RESULTS}

\section{Identification of TPH2 sequence variants}

In this study a 905-bp 5' flanking region and a 1104-bp 3' flanking region of the TPH2 gene has been sequenced. In addition to the six reported SNPs [rs4570625 (-703G/ T), rs11178997 (-473T/A), rs11178998 (90A/G), rs41317118 (92999A/G), rs17110747 $(93329 \mathrm{~A} / \mathrm{G})$, and $\mathrm{rs} 41317114(93724 \mathrm{C} / \mathrm{G})]$, the following variants were found: T/A in -454 site, G/A in -279 site, C/T in 92922 site and G/C in 93581 site, as shown in Table 2. These variants were observed only once in a heterozygotic individual (minor allele frequency $<1 \%$ ), and thus could represent mutations. Remarkably, the AA genotype at the rs41317118 locus was not detected, indicating that this genotype is rare in Han Chinese.

Table 2. Sequence variants of the human TPH2 gene identified in this current study.

\begin{tabular}{llll}
\hline Position & dbSNP ID & Region & Allele $1 / 2$ \\
\hline-703 & rs4570625 & 5' flanking region & G/T \\
-473 & rs11178997 & 5' flanking region & T/A \\
-454 & $\mathrm{~N}$ & 5' flanking region & T/A \\
-279 & $\mathrm{~N}$ & 5' flanking region & $\mathrm{G} / \mathrm{A}$ \\
90 & rs11178998 & exon1(5'-UTR) & $\mathrm{A} / \mathrm{G}$ \\
92922 & $\mathrm{~N}$ & exon11(3'- UTR) & $\mathrm{C} / \mathrm{T}$ \\
92999 & rs41317118 & exon11(3'- UTR) & $\mathrm{G} / \mathrm{A}$ \\
93329 & rs17110747 & exon11(3'- UTR) & G/A \\
93581 & $\mathrm{~N}$ & 3' flanking region & G/C \\
93724 & rs41317114 & 3' flanking region & $\mathrm{G} / \mathrm{C}$ \\
\hline
\end{tabular}

\section{Single site association analysis}

Distributions of genotype and allele frequencies of the six SNPs in schizophrenic patients and controls are summarized in Table 3. The genotype distributions of the six loci were in Hardy-Weinberg equilibrium for both patients and controls. Chi-square analysis showed significant group differences for distributions of allele $(\mathrm{P}=0.002, \mathrm{OR}=1.574,95 \% \mathrm{CI}=$ 1.185-2.089) and genotype $(\mathrm{P}=0.004)$ frequencies for $\mathrm{rs} 4570625$. These significant differences were due to a higher $\mathrm{G}$ allele frequency in patients $(48.0 \%)$ than controls $(37.7 \%)$. The OR and $95 \% \mathrm{CI}$ were both greater than 1, suggesting that an increased frequency of allele $\mathrm{G}$ conferred an increased risk of schizophrenia. Moreover, when males and females were analyzed separately, there were significant differences in distributions of allele $(\mathrm{P}=0.009, \mathrm{OR}=1.726$, $95 \% \mathrm{CI}=1.144-2.605)$ and genotype $(\mathrm{P}=0.039)$ frequencies for females but not for males $(\mathrm{P}>0.05)$, suggesting that females carrying the $\mathrm{G}$ allele were more susceptible to schizophrenia than males. There were no statistical differences in allele $(\mathrm{P}>0.05)$ and genotype $(\mathrm{P}$ $>0.05$ ) frequencies between patients and controls for rs11178997, rs11178998, rs41317118, rs17110747 and rs41317117, even when males and females were analyzed separately. 


\begin{tabular}{|c|c|c|c|c|c|}
\hline SNP ID & Schizophrenia $(\mathrm{N}=164)$ & Control $(\mathrm{N}=244)$ & $\mathrm{P}$ & OR & $95 \% \mathrm{CI}$ \\
\hline \multicolumn{6}{|c|}{ rs4570625 } \\
\hline \multicolumn{6}{|c|}{ All subjects } \\
\hline TT & $40(24.4)$ & $97(39.7)$ & 0.004 & & \\
\hline TG & $88(53.6)$ & $110(45.1)$ & & & \\
\hline GG & $36(22.0)$ & $37(15.2)$ & & & \\
\hline $\mathrm{T}$ & $168(51.2)$ & $304(62.3)$ & & & \\
\hline $\mathrm{G}$ & $160(48.8)$ & $184(37.7)$ & 0.002 & 1.574 & $1.185-2.089$ \\
\hline \multicolumn{6}{|l|}{ Male } \\
\hline TT & $21(24.1)$ & 49 (39.9) & 0.079 & & \\
\hline TG & $50(57.3)$ & $58(46.0)$ & & & \\
\hline GG & $16(18.4)$ & $19(15.1)$ & & & \\
\hline $\mathrm{T}$ & $92(52.3)$ & $156(61.9)$ & & & \\
\hline G & $82(47.1)$ & $96(38.1)$ & 0.063 & 1.448 & $0.979-2.142$ \\
\hline \multicolumn{6}{|c|}{ Female } \\
\hline $\mathrm{TT}$ & $19(24.7)$ & $48(40.7)$ & 0.039 & & \\
\hline TG & $38(49.3)$ & $52(44.1)$ & & & \\
\hline GG & $20(26.0)$ & $18(15.2)$ & & & \\
\hline $\mathrm{T}$ & $76(49.4)$ & $148(62.7)$ & & & \\
\hline \multirow{2}{*}{\multicolumn{6}{|c|}{$\begin{array}{l}\text { rs } 11178997 \\
\text { ref }\end{array}$}} \\
\hline & & & & & \\
\hline \multicolumn{6}{|c|}{ All subjects } \\
\hline TT & $121(73.8)$ & $169(69.3)$ & 0.611 & & \\
\hline TA & 37 (22.6) & $64(26.2)$ & & & \\
\hline AA & $6(3.6)$ & $11(4.5)$ & & & \\
\hline $\mathrm{T}$ & $279(85.1)$ & $402(82.4)$ & & & \\
\hline A & $49(14.9)$ & $86(17.6)$ & 0.312 & 0.821 & $0.560-1.204$ \\
\hline \multicolumn{6}{|l|}{ Male } \\
\hline TT & $65(74.7)$ & $84(66.7)$ & 0.385 & & \\
\hline TA & $17(19.5)$ & $35(27.8)$ & & & \\
\hline AA & $5(5.8)$ & $7(5.5)$ & & & \\
\hline $\mathrm{T}$ & $147(84.5)$ & 203 (80.6) & & & \\
\hline A & $27(15.5)$ & $49(19.4)$ & 0.298 & 0.761 & $0.454-1.274$ \\
\hline \multicolumn{6}{|c|}{ Female } \\
\hline TT & $56(72.7)$ & $85(72.0)$ & 0.659 & & \\
\hline TA & $20(26.0)$ & $29(24.6)$ & & & \\
\hline AA & $1(1.3)$ & $4(3.4)$ & & & \\
\hline $\mathrm{T}$ & $132(85.7)$ & $199(84.3)$ & & & \\
\hline A & $22(14.3)$ & $37(15.7)$ & 0.708 & 0.896 & $0.506-1.588$ \\
\hline \multicolumn{6}{|c|}{ rs11178998 } \\
\hline \multicolumn{6}{|c|}{ All subjects } \\
\hline AA & $121(73.8)$ & $169(69.3)$ & 0.554 & & \\
\hline AG & $38(23.2)$ & $64(26.2)$ & & & \\
\hline GG & $5(3.0)$ & $11(4.5)$ & & & \\
\hline A & $280(85.4)$ & $402(82.4)$ & & & \\
\hline G & 48 (14.6) & 86 (17.6) & 0.259 & 1.248 & $0.849-1.833$ \\
\hline \multicolumn{6}{|l|}{ Male } \\
\hline AA & 65 (74.7) & 84 (66.7) & 0.385 & & \\
\hline AG & $17(19.5)$ & $35(27.8)$ & & & \\
\hline GG & $5(5.8)$ & $7(5.5)$ & & & \\
\hline A & $147(84.5)$ & 203 (80.6) & & & \\
\hline G & $27(15.5)$ & 49 (19.4) & 0.298 & 1.314 & $0.785-2.201$ \\
\hline \multicolumn{6}{|c|}{ Female } \\
\hline AA & $56(72.7)$ & $85(72.0)$ & 0.254 & & \\
\hline $\mathrm{AG}$ & $21(27.3)$ & $29(24.6)$ & & & \\
\hline GG & $0(0)$ & $4(3.4)$ & & & \\
\hline A & $133(86.4)$ & $199(84.3)$ & & & \\
\hline G & 21 (13.6) & $37(15.7)$ & 0.580 & 1.178 & $0.660-2.101$ \\
\hline
\end{tabular}

Continued on next page 
X.M. Xu et al.

\begin{tabular}{|c|c|c|c|c|c|}
\hline SNP ID & Schizophrenia $(\mathrm{N}=164)$ & Control $(\mathrm{N}=244)$ & $\mathrm{P}$ & OR & $95 \% \mathrm{CI}$ \\
\hline \multicolumn{6}{|c|}{ rs41317118 } \\
\hline \multicolumn{6}{|c|}{ All subjects } \\
\hline AA & $0(0)$ & $0(0)$ & \multicolumn{2}{|l|}{0.996} & \\
\hline $\mathrm{AG}$ & $17(10.4)$ & $26(10.7)$ & & & \\
\hline GG & 147 (89.6) & $218(89.3)$ & & & \\
\hline A & $17(5.2)$ & $26(5.3)$ & & & \\
\hline G & $311(94.8)$ & $462(94.7)$ & 0.928 & 0.971 & $0.518-1.820$ \\
\hline \multicolumn{6}{|l|}{ Male } \\
\hline AA & $0(0)$ & $0(0)$ & \multirow[t]{4}{*}{0.812} & & \\
\hline $\mathrm{AG}$ & $13(14.9)$ & $15(11.9)$ & & & \\
\hline GG & $74(85.1)$ & $111(88.1)$ & & & \\
\hline A & $13(7.5)$ & $15(6.0)$ & & & \\
\hline $\mathrm{G}$ & $161(92.5)$ & $237(94.0)$ & 0.534 & 1.276 & $0.591-2.753$ \\
\hline \multicolumn{6}{|c|}{ Female } \\
\hline $\mathrm{AA}$ & $0(0)$ & $0(0)$ & \multirow[t]{4}{*}{0.572} & & \\
\hline $\mathrm{AG}$ & $4(5.2)$ & $11(9.3)$ & & & \\
\hline GG & $73(94.8)$ & $107(90.7)$ & & & \\
\hline A & $4(2.6)$ & $11(4.7)$ & & & \\
\hline G & 150 (97.4) & $225(95.3)$ & 0.300 & 0.546 & $0.171-1.745$ \\
\hline \multicolumn{6}{|c|}{ rs17110747 } \\
\hline \multicolumn{6}{|c|}{ All subjects } \\
\hline GG & $93(56.7)$ & $129(52.9)$ & \multirow{4}{*}{0.641} & & \\
\hline $\mathrm{AG}$ & $62(37.8)$ & $97(39.7)$ & & & \\
\hline AA & $9(5.5)$ & $18(7.4)$ & & & \\
\hline $\mathrm{G}$ & $248(75.6)$ & $355(72.7)$ & & & \\
\hline A & $80(27.4)$ & $133(27.3)$ & 0.361 & 0.861 & $0.624-1.187$ \\
\hline \multicolumn{6}{|l|}{ Male } \\
\hline GG & $48(55.2)$ & 65 (51.6) & \multirow[t]{4}{*}{0.873} & & \\
\hline $\mathrm{AG}$ & $33(37.9)$ & $52(41.3)$ & & & \\
\hline AA & $6(6.9)$ & $9(7.1)$ & & & \\
\hline $\mathrm{G}$ & $129(74.1)$ & $182(2.7)$ & & & \\
\hline A & $45(25.9)$ & $70(27.8)$ & 0.662 & 0.907 & $0.586-1.404$ \\
\hline \multicolumn{6}{|c|}{ Female } \\
\hline GG & $45(58.4)$ & $64(54.2)$ & \multirow[t]{4}{*}{0.548} & & \\
\hline $\mathrm{AG}$ & $29(37.7)$ & $45(38.1)$ & & & \\
\hline $\mathrm{AA}$ & $3(3.9)$ & $9(7.6)$ & & & \\
\hline G & $119(77.3)$ & $173(73.3)$ & & & \\
\hline A & $35(22.7)$ & $63(26.7)$ & 0.377 & 0.808 & $0.503-1.298$ \\
\hline \multicolumn{6}{|c|}{ rs41317114 } \\
\hline \multicolumn{6}{|c|}{ All subjects } \\
\hline GG & $121(73.8)$ & $196(80.3)$ & \multirow[t]{4}{*}{0.230} & & \\
\hline $\mathrm{CG}$ & $41(25.0)$ & $44(18.0)$ & & & \\
\hline $\mathrm{CC}$ & $2(1.2)$ & $4(1.6)$ & & & \\
\hline G & $283(86.3)$ & $436(89.3)$ & & & \\
\hline $\mathrm{C}$ & $45(13.7)$ & $52(10.7)$ & 0.185 & 1.333 & $0.871-2.042$ \\
\hline Male & & & & & \\
\hline GG & $66(75.9)$ & $100(9.4)$ & 0.586 & & \\
\hline $\mathrm{CG}$ & $20(23.0)$ & $23(18.2)$ & & & \\
\hline $\mathrm{CC}$ & $1(1.1)$ & $3(2.4)$ & & & \\
\hline G & $152(87.4)$ & $223(88.5)$ & & & \\
\hline $\mathrm{C}$ & $22(12.6)$ & $29(11.5)$ & 0.723 & 1.113 & $0.616-2.010$ \\
\hline Female & & & & & \\
\hline GG & $55(71.4)$ & $96(81.4)$ & 0.269 & & \\
\hline $\mathrm{CG}$ & $21(27.3)$ & $21(17.8)$ & & & \\
\hline $\mathrm{CC}$ & $1(1.3)$ & $1(0.8)$ & & & \\
\hline G & $131(85.1)$ & $213(90.2)$ & & & \\
\hline $\mathrm{C}$ & $23(14.9)$ & $23(9.8)$ & 0.121 & 1.626 & $0.877-3.015$ \\
\hline
\end{tabular}

Data represent N (\%). 


\section{LD mapping}

Figure 1 shows the data from pairwise LD analyses between schizophrenia and control groups across six SNPs, as represented by the LD coefficient (D'). Strong LD was observed between rs4570625, rs11178997 and rs11178998 in both groups, while strong LD between rs41317118, rs17110747 and rs41317114 was present only in controls but not in schizophrenia patients, suggesting a possible disease association. Accordingly, we identified two haplotype blocks for further investigation via haplotype association analysis.

A

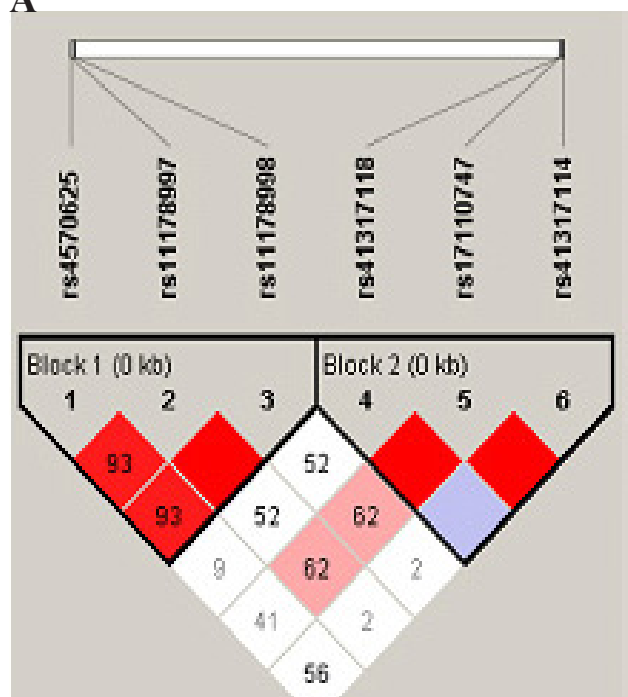

B
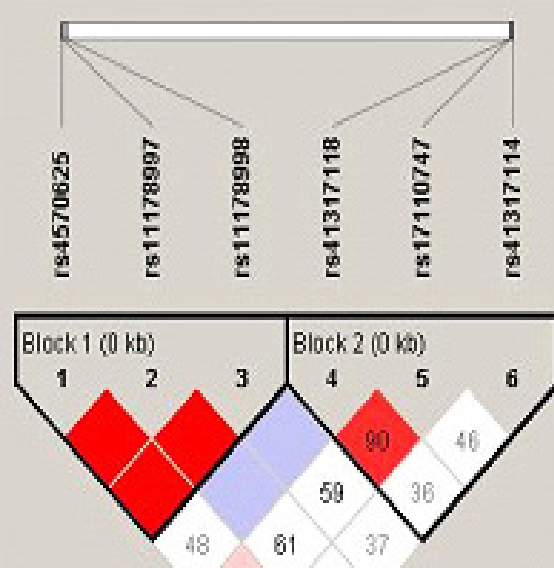

54

$54 \bigcirc 25$

Figure 1. Linkage disequilibrium and D' for six SNPs in TPH2 in control subjects (A) and patients with schizophrenia (B). Empty squares indicate D' $=1$.

\section{Haplotype association analysis}

Table 4 shows the results of the haplotype analysis. Significant group differences were observed for haplotypes GTA $(\mathrm{P}=0.001, \mathrm{OR}=1.591,95 \% \mathrm{CI}=1.198-2.114)$ and TTA $(\mathrm{P}=0.014, \mathrm{OR}=0.700,95 \% \mathrm{CI}=0.525-0.933)$ in block 1 . The frequency of haplotype GTA was greater in schizophrenic patients $(0.487)$ than in controls $(0.374)$, and the OR and $95 \% \mathrm{CI}$ were both greater than 1, suggesting that an increased frequency of haplotype GTA conferred an increased risk of paranoid schizophrenia. Furthermore, significant group differences in distribution were detected in females $(\mathrm{P}<0.05)$ but not in males $(\mathrm{P}$ $>0.05)$, suggesting that females with haplotype GTA were more susceptible to paranoid schizophrenia than males. There were no significant group differences for haplotype TAG in block 1 or for any haplotypes in block 2, even when males and females were analyzed separately. 
Table 4. Haplotype block analyses in schizophrenia and control cases.

\begin{tabular}{|c|c|c|c|c|c|c|}
\hline Haplotype block & Haplotype $^{\mathrm{a}}$ & Schizophrenia & Control & $\mathrm{P}$ & OR & $95 \% \mathrm{CI}$ \\
\hline \multirow[t]{12}{*}{ Block1: SNPs 1-3 } & GTA & & & & & \\
\hline & All subjects & 0.487 & 0.374 & 0.001 & 1.591 & $1.198-2.114$ \\
\hline & Male & 0.471 & 0.381 & 0.063 & 1.448 & $0.979-2.142$ \\
\hline & Female & 0.505 & 0.367 & 0.007 & 1.769 & $1.171-2.674$ \\
\hline & TTA & & & & & \\
\hline & All subjects & 0.364 & 0.450 & 0.014 & 0.700 & $0.525-0.933$ \\
\hline & Male & 0.374 & 0.425 & 0.291 & 0.808 & $0.544-1.201$ \\
\hline & Female & 0.352 & 0.476 & 0.015 & 0.599 & $0.394-0.911$ \\
\hline & TAG & & & & & \\
\hline & All subjects & 0.146 & 0.173 & 0.294 & 0.814 & $0.553-1.196$ \\
\hline & Male & 0.155 & 0.194 & 0.293 & 0.761 & $0.454-1.274$ \\
\hline & Female & 0.135 & 0.151 & 0.667 & 0.879 & $0.492-1.573$ \\
\hline \multirow[t]{16}{*}{ Block 1: SNPs 4-6 } & GGG & & & & & \\
\hline & All subjects & 0.625 & 0.622 & 0.945 & 1.078 & $0.806-1.442$ \\
\hline & Male & 0.624 & 0.607 & 0.731 & 1.118 & $0.750-1.667$ \\
\hline & Female & 0.626 & 0.640 & 0.782 & 1.111 & $0.723-1.709$ \\
\hline & GAG & & & & & \\
\hline & All subjects & 0.186 & 0.218 & 0.273 & 0.793 & $0.557-1.130$ \\
\hline & Male & 0.175 & 0.218 & 0.276 & 0.697 & $0.423-1.151$ \\
\hline & Female & 0.198 & 0.216 & 0.679 & 0.918 & $0.555-1.517$ \\
\hline & GGC & & & & & \\
\hline & All subjects & 0.128 & 0.105 & 0.305 & 1.143 & $0.735-1.776$ \\
\hline & Male & 0.118 & 0.115 & 0.933 & 0.920 & $0.495-1.711$ \\
\hline & Female & 0.140 & 0.092 & 0.142 & 1.383 & $0.727-2.629$ \\
\hline & AAG & & & & & \\
\hline & All subjects & 0.048 & 0.053 & 0.779 & 0.841 & $0.437-1.620$ \\
\hline & Male & 0.075 & 0.060 & 0.534 & 1.306 & $0.603-2.830$ \\
\hline & Female & 0.018 & 0.046 & 0.167 & 0.091 & $0.008-1.100$ \\
\hline
\end{tabular}

${ }^{\mathrm{a}}$ Haplotypes with frequency $<0.01$ were not included in analysis.

\section{DISCUSSION}

To our knowledge, this is the first study to investigate an association between paranoid schizophrenia in Han Chinese and specific SNPs in the TPH2 gene, including rs4570625, rs11178997, rs11178998, rs41317118, rs17110747 and rs41317114. These six SNPs were located in the regulatory region, including the promoter region, 5' UTR and $3^{\prime}$ flanking region, which do not alter the protein sequence, but might be involved in regulation of gene expression. We identified three different haplotypes of the human TPH2 promoter: GTA, TTA and TAG, supporting previous findings (Scheuch et al., 2007). TTA was the most prevalent TPH2 promoter haplotype in Han Chinese.

In the present study, we successfully identified significant associations in the genotype distributions and allele frequencies of rs4570625 with paranoid schizophrenia in Han Chinese. Schizophrenic patients had an increased frequency of the G allele, suggesting that this allele confers an increased risk of schizophrenia. A previous study by Yoon and Kim (2009) showed that the homozygous $\mathrm{G}$ allele frequency was significantly higher in suicidal depressed patients than in controls, and increased frequency of this allele conferred an increased risk of suicide. The reason maybe that rs 450625 is situated in the promoter region of the TPH2 gene, which impacts expression of TPH2 by modifying binding sites for transcription factors (e.g., POU3F2, a crucial regulator of TPH2 expression) (Lin et al., 2007; Sacco et al., 2007; Chen et al., 2008). A postmortem study revealed a trend toward higher TPH2 expression in the dorsolateral prefrontal cortex (Brodmann Area 46) in schizophrenic patients relative to controls (De Luca et al., 2005b). 
Moreover, an association was also observed between paranoid schizophrenia in Han Chinese and haplotype frequencies of GTA and TTA combined with rs4570625-rs11178997rs1178998. Such haplotypes include rs4570625, which was discussed earlier. The SNP in the rs11178997 site is also in the POU3F2 binding site, and an electrophoretic mobility shift assay revealed reduced binding of the transcription factor POU3F2 to the A allele, suggesting that the human TPH2 promoter polymorphism rs11178997 impacts gene expression (Lin et al., 2007; Scheuch et al., 2007). A recent study showed that SNP rs1178998 might affect expression of the TPH2 gene at the post transcriptional level, and the three SNPs mentioned above differentially regulated gene expression via haplotype-specific effects on transcriptional activity of the TPH2 gene (Chen et al., 2008).

It is noteworthy that we observed an association with paranoid schizophrenia in females only in the genotype distributions and allele frequency of rs4570625 and in the haplotype frequencies of GTA and TTA corresponding to rs4570625- rs11178997-rs11178998, suggesting that females with G alleles or haplotype GTA were more susceptible to paranoid schizophrenia than males. The epidemiological survey showed a significantly higher incidence of mental illness in females. The reasons underlying this sex difference are unclear and require further study, but may be related to estrogen levels.

In the present study, we found no significant differences in genotypic distributions or allelic frequencies of rs11178997, rs11178998, rs41317118, rs17110747 and rs41317114. Furthermore, frequencies of haplotypes constructed with rs41317118-rs17110747-rs41317114 were not associated with schizophrenia, consistent with other findings (De Luca et al., 2005a; Shiroiwa et al., 2010; Serretti et al., 2011).

Prior to our study, no studies had reported an association between genetic variations in the TPH2 gene and schizophrenia (De Luca et al., 2005a; Higashi et al., 2007; Shiroiwa et al., 2010; Tee et al., 2010, Kim and Yoon, 2011; Zhang et al., 2011). There are several possible explanations for our novel results. First, unlike in previous studies, SNPs in the current study were in the regulatory region of the TPH2 gene and therefore could affect gene expression. Second, schizophrenia is a heterozygous disease, and clinical heterogeneity of disease phenotypes may prevent a more detailed understanding of genetic structure (Cherlyn et al., 2010). We indeed specifically studied the paranoid subtype of schizophrenia. The relatively small sample size of the current study limits the possibility to generalize our results, and these data should be replicated in an independent study.

In conclusion, we found associations between paranoid schizophrenia in Han Chinese and the genotype distributions and allele frequency of rs4570625 and haplotype frequencies of GTA and TTA combined with rs4570625-rs11178997-rs1178998. This is the first report to show that specific SNPs in TPH2 are associated with paranoid schizophrenia.

\section{ACKNOWLEDGMENTS}

Research supported by China Medical University and Kaiyuan Mental Hospital in Liaoning Province.

\section{REFERENCES}

Abi-Dargham A, Laruelle M, Aghajanian GK, Charney D, et al. (1997). The role of serotonin in the pathophysiology and 
treatment of schizophrenia. J. Neuropsychiatry Clin. Neurosci. 9: 1-17.

Allen NC, Bagade S, McQueen MB, Ioannidis JP, et al. (2008). Systematic meta-analyses and field synopsis of genetic association studies in schizophrenia: the SzGene database. Nat. Genet. 40: 827-834.

Anttila S, Kampman O, Illi A, Rontu R, et al. (2007). Association between 5-HT2A, TPH1 and GNB3 genotypes and response to typical neuroleptics: a serotonergic approach. BMC Psychiatry 7: 22.

Brown SM, Peet E, Manuck SB, Williamson DE, et al. (2005). A regulatory variant of the human tryptophan hydroxylase-2 gene biases amygdala reactivity. Mol. Psychiatr. 10: 884-8, 805.

Canli T, Congdon E, Gutknecht L, Constable RT, et al. (2005). Amygdala responsiveness is modulated by tryptophan hydroxylase-2 gene variation. J. Neural Transm. 112: 1479-1485.

Cardno AG and Gottesman II (2000). Twin studies of schizophrenia: from bow-and-arrow concordances to star wars Mx and functional genomics. Am. J. Med. Genet. 97: 12-17.

Chen GL, Vallender EJ and Miller GM (2008). Functional characterization of the human TPH2 5' regulatory region: untranslated region and polymorphisms modulate gene expression in vitro. Hum. Genet. 122: 645-657.

Cherlyn SY, Woon PS, Liu JJ, Ong WY, et al. (2010). Genetic association studies of glutamate, GABA and related genes in schizophrenia and bipolar disorder: a decade of advance. Neurosci. Biobehav. Rev. 34: 958-977.

De Luca V, Voineskos D, Wong GW, Shinkai T, et al. (2005a). Promoter polymorphism of second tryptophan hydroxylase isoform (TPH2) in schizophrenia and suicidality. Psychiatry Res. 134: 195-198.

De Luca V, Likhodi O, Van Tol HH, Kennedy JL, et al. (2005b). Tryptophan hydroxylase 2 gene expression and promoter polymorphisms in bipolar disorder and schizophrenia. Psychopharmacology 183: 378-382.

Goertzelet BN, Pennachin C, de Souza CL, Gurbaxani B, et al. (2006). Combinations of single nucleotide polymorphisms in neuroendocrine effector and receptor genes predict chronic fatigue syndrome. Pharmacogenomics 7: 475-483.

Goghari VM, Sponheim SR and Macdonald AW, III (2010). The functional neuroanatomy of symptom dimensions in schizophrenia: a qualitative and quantitative review of a persistent question. Neurosci. Biobehav. Rev. 34: 468-486.

Gutknecht L, Jacob C, Strobel A, Kriegebaum C, et al. (2007). Tryptophan hydroxylase-2 gene variation influences personality traits and disorders related to emotional dysregulation. Int. J. Neuropsychopharmacol. 10: 309-320.

Herrmann MJ, Huter T, Müller F, Mühlberger A, et al. (2007). Additive effects of serotonin transporter and tryptophan hydroxylase-2 gene variation on emotional processing. Cereb. Cortex 17: 1160-1163.

Heston LL (1966). Psychiatric disorders in foster home reared children of schizophrenic mothers. Br. J. Psychiatr. 112: 819-825.

Higashi S, Ohnuma T, Shibata N, Higashi M, et al. (2007). No genetic association between tryptophan hydroxylase 2 gene polymorphisms and Japanese schizophrenia. Psychiatr. Genet. 17: 123.

Kennedy MA, Miller AL, Rogers G, Luty S, et al. (2003). Polymorphic variants and association analysis of TPH2, brain tryptophan hydroxylase. Neuropsychiatric Genet. 122: 69.

Kim YK and Yoon HK (2011). Effect of serotonin-related gene polymorphisms on pathogenesis and treatment response in Korean schizophrenic patients. Behav. Genet. 41: 709-715.

Li D and He L (2006a). Further clarification of the contribution of the tryptophan hydroxylase (TPH) gene to suicidal behavior using systematic allelic and genotypic meta-analyses. Hum. Genet. 119: 233-240.

Li D and He L (2006b). Meta-analysis shows association between the tryptophan hydroxylase (TPH) gene and schizophrenia. Hum. Genet. 120: 22-30.

Lin YM, Chao SC, Chen TM, Lai TJ, et al. (2007). Association of functional polymorphisms of the human tryptophan hydroxylase 2 gene with risk for bipolar disorder in Han Chinese. Arch. Gen. Psychiatry 64: 1015-1024.

Maron E, Tõru I, Must A, Tasa G, et al. (2007). Association study of tryptophan hydroxylase 2 gene polymorphisms in panic disorder. Neurosci. Lett. 411: 180-184.

Mössner R, Müller-Vahl KR, Döring N and Stuhrmann M (2007). Role of the novel tryptophan hydroxylase-2 gene in Tourette syndrome. Mol. Psychiatr. 12: 617-619.

Paik I, Toh K, Kim J and Lee C (2000). TPH gene may be associated with suicidal behavior, but not with schizophrenia in the Korean population. Hum. Hered. 50: 365-369.

Reuter M, Kuepper Y and Hennig J. (2007). Association between a polymorphism in the promoter region of the TPH2 gene and the personality trait of harm avoidance. Int. J. Neuropsychopharmacol. 10: 401-404.

Sacco R, Papaleo V, Hager J, Rousseau F, et al. (2007). Case-control and family-based association studies of candidate genes in autistic disorder and its endophenotypes: TPH2 and GLO1. BMC. Med. Genet. 8: 11.

Scheuch K, Lautenschlager M, Grohmann M, Stahlberg S, et al. (2007). Characterization of a functional promoter polymorphism of the human tryptophan hydroxylase 2 gene in serotonergic raphe neurons. Biol. Psychiatr. 62: 1288-1294.

Schwab SG and Wildenauer DB (2008). Research on causes for schizophrenia: are we close? Schizophr. Res. 102: 29-30. Serretti A, Chiesa A, Porcelli S, Han C, et al. (2011). Influence of TPH2 variants on diagnosis and response to treatment in 
patients with major depression, bipolar disorder and schizophrenia. Psychiatr. Res. 189: 26-32.

Shiroiwa K, Hishimoto A, Mouri K, Fukutake M, et al. (2010). Common genetic variations in TPH1/TPH2 genes are not associated with schizophrenia in Japanese population. Neurosci. Lett. 472: 194-198.

Smith AK, White PD, Aslakson E, Vollmer-Conna U, et al. (2006). Polymorphisms in genes regulating the HPA axis associated with empirically delineated classes of unexplained chronic fatigue. Pharmacogenomics 7: 387-394.

Sullivan PF, Kendler KS and Neale MC (2003). Schizophrenia as a complex trait: evidence from a meta-analysis of twin studies. Arch. Gen. Psychiatr. 60: 1187-1192.

Tee SF, Chow TJ, Tang PY and Loh HC (2010). Linkage of schizophrenia with TPH2 and 5-HTR2A gene polymorphisms in the Malay population. Genet. Mol. Res. 9: 1274-1278.

Tsuang MT, Kendler KK and Gruenberg AM (1985). DSM-III schizophrenia: is there evidence for familial transmission. Acta Psychiatr. Scand. Suppl. 319: 77-83.

Walitza S, Renner TJ, Dempfle A, Konrad K, et al. (2005). Transmission disequilibrium of polymorphic variants in the tryptophan hydroxylase-2 gene in attention-deficit/hyperactivity disorder. Mol. Psychiatr. 10: 1126-1132.

Walther DJ, Peter JU, Bashammakh S, Hortnagl H, et al. (2003). Synthesis of serotonin by a second tryptophan hydroxylase isoform. Science 299: 76.

Yoon HK and Kim YK (2009). TPH2 -703G/T SNP may have important effect on susceptibility to suicidal behavior in major depression. Prog. Neuropsychopharmacol. Biol. Psychiatr. 33: 403-409.

Zaboli G, Jonsson EG, Gizatullin R, Asberg M, et al. (2006). Tryptophan hydroxylase-1 gene variants associated with schizophrenia. Biol. Psychiatr. 60: 563-569.

Zhang C, Li Z, Shao Y, Xie B, et al. (2011). Association study of tryptophan hydroxylase-2 gene in schizophrenia and its clinical features in Chinese Han population. J. Mol. Neurosci. 43: 406-411.

Zill P, Büttner A, Eisenmenger W, Bondy B, et al. (2004a). Regional mRNA expression of a second tryptophan hydroxylase isoform in postmortem tissue samples of two human brains. Eur. Neuropsychopharmacol. 14: 282-284.

Zill P, Büttner A, Eisenmenger W, Möller HJ, et al. (2004b). Single nucleotide polymorphism and haplotype analysis of a novel tryptophan hydroxylase isoform (TPH2) gene in suicide victims. Biol. Psychiatry 56: 581-586.

Zill P, Baghai TC, Zwanzger P, Schule C, et al. (2004c). SNP and haplotype analysis of a novel tryptophan hydroxylase isoform (TPH2) gene provide evidence for association with major depression. Mol. Psychiatr. 9: 1030-1036. 